\title{
The November 2021 issue
}

\section{Charles B. Hodges ${ }^{1}$ (1)}

Published online: 26 October 2021

(c) Association for Educational Communications \& Technology 2021

Welcome to the November 2021 issue of TechTrends! This issue, the last issue in the 2021 volume year, is a special issue on Blended \& Distance Learning for P-12 Contexts, guest edited by Kalianne L. Neumann, Cecil R. Short, Jacob A. Hall, and Frances Alvarado-Albertorio. I really appreciate the months of work that this team did taking this issue from concept to completion. You can read more about the end result of their work in their Guest Editors' Notes. In addition to the specially themed content, the issue contains entries in the Conference Planning, Graduate Member Musings, and Book Reviews columns.

As always, if you are interested in submitting a manuscript to TechTrends, or if you want to be a reviewer, please contact me. Encourage your colleagues to submit their work to the journal, to read TechTrends, and to consider joining AECT! If you have a question about the journal, my phone number is 912-478-0497 and my email address is chodges@georgiasouthern.edu. Email is the best way to reach me. Also, you can follow TechTrends on Twitter: @ AECTTechTrends.

Publisher's Note Springer Nature remains neutral with regard to jurisdictional claims in published maps and institutional affiliations.
Charles B. Hodges

chodges@georgiasouthern.edu

1 Georgia Southern University, Statesboro, GA, USA 